\title{
Forgotten coast, forgotten people: sustainable development and disproportionate impacts from Hurricane Michael in Gulf County, Florida
}

\author{
Chad S. Boda ${ }^{1}$ (D) . Murray W. Scown ${ }^{2} \cdot$ Turaj Faran $^{1}$
}

Received: 10 May 2021 / Accepted: 21 October 2021 / Published online: 29 October 2021

(c) The Author(s) 2021, corrected publication 2021

\begin{abstract}
A central challenge for sustainable development is how societies are to avoid, minimize or address impacts from anthropogenic climate change. However, competing perspectives on "what should be sustained" lead to widely different understandings of what mitigation, adaptation and loss and damage entail and how best to approach them. We provide a novel conceptual and empirical comparison of two contrasting sustainable development-based approaches to the study of impacts from climate-related extreme events: Capital Theory and capability-based Human Development. We use our analysis of immediate residential property value and housing capacity impacts caused by Hurricane Michael in Gulf County, Florida, to demonstrate how the sustainable development theory used to assess and interpret impacts greatly affects the identification of whom and where is objectively "most impacted." Through a comparison of the two approaches, we identify relative advantages and disadvantages, emphasizing that while both provide coherent, comprehensive, and integrative approaches to climate-related impact assessment, the capability approach is much less likely to lead researchers and practitioners to overlook the most disadvantaged communities when compared to Capital Theory.
\end{abstract}

Keywords Climate change $\cdot$ Capital theory $\cdot$ Capabilities approach $\cdot$ Loss and damage . Disproportionality $\cdot$ Housing $\cdot$ Disasters

\section{Introduction}

Evidence is mounting that anthropogenic climate change (CC) is already causing geographically uneven and socially disproportionate impacts in different places around the world (IPCC 2018). However, the kinds of impacts considered relevant to CC policy and practice, e.g., economic vs. non-economic (Serdeczny et al. 2018), tangible versus intangible

Chad S. Boda

chad.boda@lucsus.lu.se

1 Lund University Centre for Sustainability Studies, LUCSUS, Lund University, Box 170, SE-221 00 Lund, Sweden

2 Copernicus Institute of Sustainable Development, Utrecht University, Utrecht, The Netherlands 
(Tschakert et al. 2019), and at what scale, remains contested terrain. The way evidence of impacts is interpreted by researchers and policymakers will have important implications for where and whom is considered "most impacted," and thus for what is considered a prudent policy response to address climate-related impacts when they occur (Thomas et al. 2020). In the context of sustainable development, addressing this question means clarifying "what should be sustained" when attempting to avoid, minimize or address impacts from CC.

Sustainable development offers a fully comprehensive, integrative, and coherent approach to understanding and addressing anthropogenic climate change-driven impacts (Boda et al. 2020). Multiple theories of sustainable development are (implicitly) informing research and practice in this area, each with a unique set of core concepts, evaluative criteria, informational requirements, and related policy prescriptions (Boda et al. 2021). Two of the main approaches include: (1) Capital Theory, a utilitarian economic theory that prioritizes maintaining a society's aggregate productivity through its capital stocks; and (2) the capabilities approach to Human Development (from now on, capabilities approach), a non-utilitarian welfare theory that prioritizes improving the substantive freedom (i.e., capabilities) available to individuals in society, starting with the least-well-off. Outside, or rather, between, these two approaches, a third unique body of work exists that emphasizes numerous heterogeneous ways in which CC impacts may manifest, which has been labelled the "wish-list of valid concerns" (Boda et al. 2021). While the spectrum of ideas that make up this body of work are not as internally coherent as the main two approaches, its most notable and consistent characteristic is a concern with the place- and cultural-specificity of many impacts from CC (see, e.g., Tschakert et al. 2017; Barnett et al. 2016). This leads some of its proponents to develop extensive lists of different types of impacts from CC that are supposedly incommensurable (e.g., Tschakert et al. 2019). How best to handle measurement and monitoring of heterogeneous impacts from CC remains an important topic of contention in loss and damage circles, as it is essential if a catalog of climate-related harm is ever to materialize (Otto et al. 2020). The current study, as explained below, maintains a focus on comparing the two main approaches; however, when discussing the relative (dis-) advantages of each approach, we highlight how each attempt to provide a satisfactory resolution to the on-going "wish-list" debate over how best to conceptualize, measure and ultimately address the heterogeneous impacts from CC.

It is well-known that there are differences in how competing theories conceptualize, measure and seek to address development related challenges (see, e.g., Greig et al. 2007, Ch. 11). Broadly speaking, economic-based approaches have dominated scholarship on the assessment of impacts from climate change (McNamara and Jackson 2019; Boda et al. 2021). However, recent developments in the area of Disaster Risk Reduction (DRR) have argued for impact assessment approaches that disaggregate impacts and highlight the most vulnerable, with some explicitly championing the capabilities approach to impact assessment (Ton et al. 2020; Gardoni and Murphy 2008; 2009). Still, use of the capabilities approach even within DRR studies remains scarce (Ton et al. 2020). In the context of climate-related impacts relevant for the Paris Agreement and loss and damage research, the explicit implications of adopting such varying approaches in interpreting disproportionality and differences in severity have not been empirically researched.

Empirical evidence is required to understand the comparative advantages and disadvantages of competing DRR or loss and damage approaches at the broader level of development strategies and priorities, not only at the level of appropriate metrics and tactics within DRR. Indeed, DRR itself needs to be situated; that is, while DRR is indispensable as a toolbox for avoiding, minimizing, and addressing risks from $\mathrm{CC}$, it generally lacks orientation regarding how such activities as mitigation, adaptation and addressing loss and 
damage from $\mathrm{CC}$ contribute to broader normative development strategies, which theories of sustainable development provide (see Boda et al. 2020). These levels, however, are of course intertwined. Theoretically speaking, the development strategy one adheres to should determine what the appropriate tools and metrics for assessment are, which in turn will guide recovery responses. However, empirically, there are very few studies assessing the same event from two different development approaches and discussing in what ways the assessments differ and how this could impact post-event response priorities (for exceptions see, e.g., Gardoni and Murphy 2010). More evidence of the advantages and disadvantages of competing sustainable development approaches to CC-impact studies will furthermore help clarify the consequences for CC-impact researchers, and the policies that flow from this research, of adopting, implicitly or explicitly, a particular approach.

We here empirically assess the impacts of Hurricane Michael to Gulf County's (Florida, USA) residential properties through three different analytical impact indicators (total property value losses, proportional property value losses, and loss of residential units or newly vacant residential properties), which we apply to parcel-level property data collected by the Gulf County Property Appraiser before and after the hurricane. We then interpret the results from the perspective of two contrasting approaches to sustainable development, namely Capital Theory and the capabilities approach. We discuss how these competing perspectives lead to different appraisals of what defines a "highly impacted" area, as well as how they have the propensity to skew toward certain types of information and thus the properties and people represented by this information. We conclude with a reasoned and comparative appraisal of the two approaches.

\section{Materials and methods}

\subsection{Over-view of Hurricane Michael impacts}

Hurricane Michael made landfall in the Florida Panhandle on October 10, 2018, as the strongest storm of the 2018 hurricane season and the strongest ever to make landfall in October in the USA. It was also the only category 5 storm on record to make landfall along this region of Florida, affectionately known as the "Forgotten Coast." More than two years later, many communities impacted by the storm are only beginning the process of longterm recovery.

The scale and type of impacts seen in the wake of Hurricane Michael are indicative of what model projections suggest will become more likely as climate change progresses, with tropical cyclones likely to increase in intensity in terms of wind speeds, storm surge and rainfall (Patricola and Wehner 2018; IPCC 2018). Post-storm analysis of Hurricane Michael showed that storm surge reached 9-14 feet $(2.7-4.3 \mathrm{~m})$ above ground level in the hardest hit areas along the coast, easily topping the local barrier island sand-dune systems that normally acts as a protective barrier against the impacts of coastal storms (Beven et al. 2018.). An impact survey conducted directly after the storm by Prevatt and Roueche (2019) showed that storm surge led to catastrophic flooding and extensive damage to coastal infrastructure and residences largely located seaward of the Coastal Construction Control Line, many of which were built prior to Florida Building Code implementation and placed in high-risk areas. Hurricane Michael's high wind speeds, which may have reached $155 \mathrm{mph}$ near the eyewall, also led to extensive impacts to housing and other infrastructure. Prevatt and Roueche (2019, pp. 19-20) found that nearly $50 \%$ of the structures they surveyed after 
the storm had experienced wind speeds exceeding 700-year wind-speed design levels, but the degree of impact was highly uneven across the impacted region, noting that "regardless of building type and peak wind speed, post-FBC [Florida Building Code] buildings perform better... [than] pre-FBC buildings" (p. 26). For example, roof sheathing or roof structure failure were "rare in post-FBC homes, even though wind speeds were close to or exceeded design for many of the homes" while such failures "occurred in about 1 in 5 preFBC homes" (p. 28). High wind speeds also led to the destruction of thousands of acres of vegetable crops across Florida, Georgia and Alabama (Avila 2019) and the toppling of hundreds of square miles of timber resources and protected forest (e.g. extensive impacts to endangered longleaf pines stands (Pinus palustris), see Zampieri et al. 2020).

In many areas, storm impacts far exceeded the budgetary capacities of highly impacted city and county governments, in a state where local financial capacity for ecological restoration, climate adaptation and disaster preparation and response is highly uneven and sometimes severely lacking (Boda and Jerneck 2019; Boda 2018). In the aggregate, Hurricane Michael was registered as a "billion dollar" disaster according to the National Center for Environmental Information, with $\$ 25.5$ billion in losses (NOAA 2020). Similarly, the Em-Dat database registered the storm as causing \$16 billion in losses. However, the distribution of these effects was highly uneven. Large portions of the total impact amounts came from agricultural and forestry impacts resulting from high wind speeds (FDACS 2018), as noted above. A smaller but no less significant portion of these reported impacts comes from structural damages, including devastating impacts to commercial and residential properties and debris clearance costs. The National Hurricane Center's final synopsis of Hurricane Michael noted that Gulf County was among the three hardest hit counties in terms of structural impacts, along with Bay County to the west, and Jackson County to the north, with Gulf County affected the most in per capita terms (Beven et al. 2018).

\subsection{Study area: Gulf County}

Gulf County is in the northwestern "Panhandle" region of Florida, in the southeastern USA (Fig. 1). Gulf County is a predominantly rural county with a population of just over 13,500 residents. Per capita income is just over $\$ 21,000$ while median household income is around $\$ 44,000$. Roughly, $15 \%$ of Gulf County's population lives in poverty (U.S. Census Bureau 2021). As previously mentioned, it was considered among the most heavily impacted counties on a per-capita basis by Hurricane Michael (Beven et al. 2018). The most recent census indicates that, since Hurricane Michael made landfall in October 2018, Gulf County's population has decreased by over $15 \%$ (U.S. Census Bureau 2021).

\subsection{Analysis of housing impacts}

We focus on housing impacts for three main reasons. First, research has consistently shown that impacts to housing are both a common and deeply significant impact occurring as a result of tropical cyclones and other natural disasters (Comerio 1997; Peacock et al. 2014). Second, in the context of the USA, housing is commonly a major source of wealth for many households, and losses in its value can have significant implications for household financial security, even inter-generationally (Wolff 2016). Finally, having access to adequate housing is a crucial conversion factor for many other essential social capabilities, including securing income-generating employment and maintaining physical and mental health (Winston and Eastaway 2008). The question of adequate 


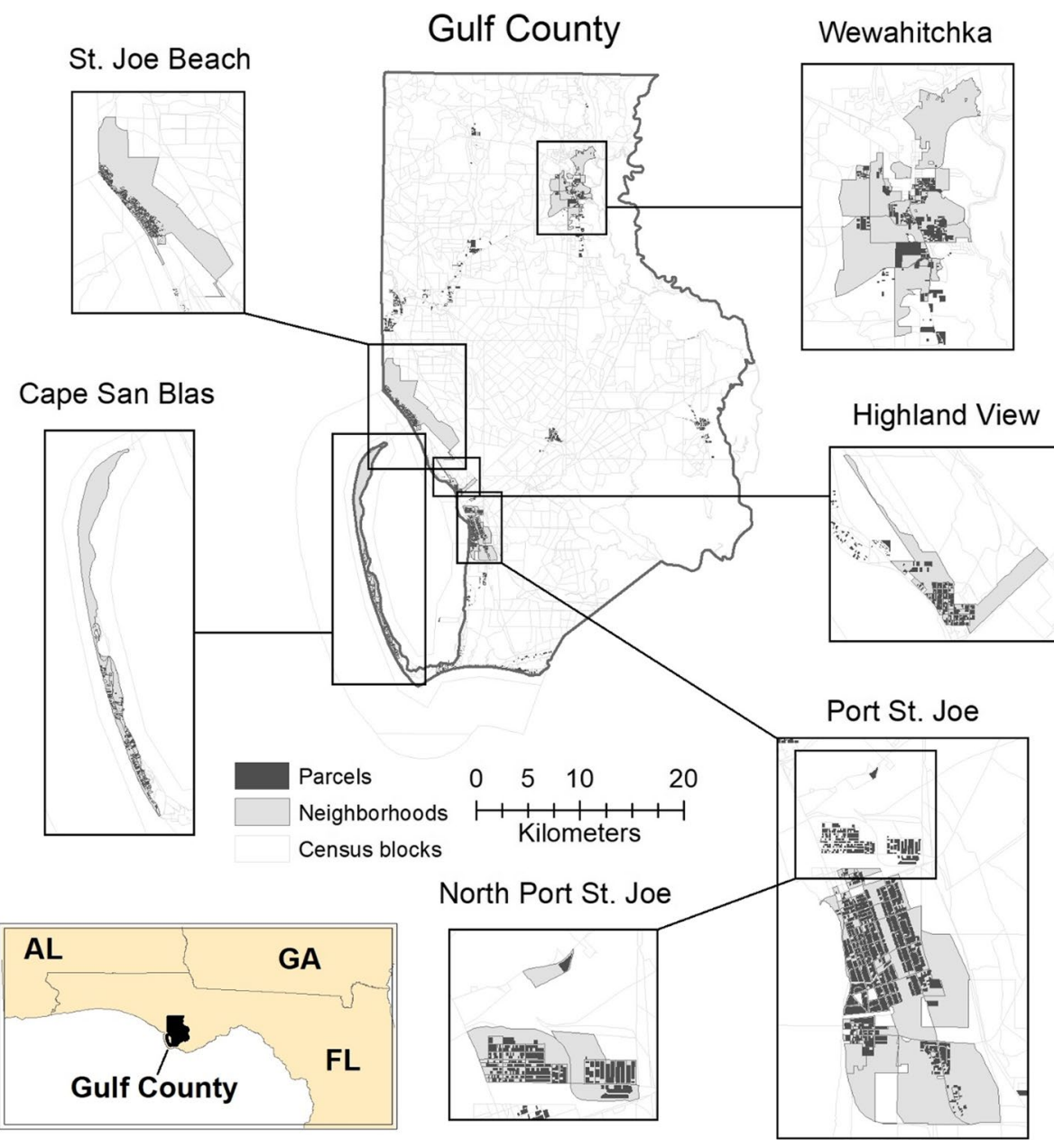

Fig. 1 Spatial boundaries of Gulf County, residential parcels and six neighborhoods analyzed. Dark gray filled shapes are all 2018 residential parcels in Gulf County. Light gray filled shapes are census blocks aggregated to analyze six neighborhoods, which are shown as insets. Bottom left inset shows location of Gulf County in the Florida Panhandle, USA. Note that North Port St. Joe was analyzed separately from what we refer to as Port St. Joe, and what we label St. Joe Beach includes the Beacon Hill locality

and affordable housing is widely viewed as central to managing future climate risks, recognizing that the housing question, particularly in developing countries, will interact with and be exacerbated by increasing climate hazards (e.g., heat waves, tropical cyclones), generally impacting the least-well-off most severely (IPCC 2018). Of course, a focus on housing certainly does not capture all significant impacts, including those that may affect the most vulnerable residents, such as elderly, people with disabilities, and low-income renters (Ton et al. 2020). Because of this, we are not claiming to reveal all the important differences between Capital Theory and the capabilities approaches when it comes to impact of climate-related extreme events. Our claim is more modest but still important. We show, using housing as an example, how the concepts and metrics in these competing approaches promote either exclusion or inclusion of impacts on 
particular portions of the population, which clearly has implications for inter alia recovery policy at a variety of scales.

We analyze housing impacts using three different impact indicators. First, we analyze total residential property value losses (i.e., aggregate monetary losses). This is taken as an indication of the quantitative severity of residential property impacts; that is, the higher the total monetary losses, the higher the impact severity. Second, we analyze proportional residential property value losses (i.e., monetary losses as a percentage of total property value). This is taken an indication of the qualitative severity of residential property impacts; that is, the higher the proportion of total property value lost, the higher the impact severity. Third, we analyze the loss of residential units (i.e., newly vacant or lost residential properties). This is taken as an indication of the severity of impacts to housing capacity; that is, the higher the percentage of residential units lost, the higher the impact severity. We note here that just because an indicator is itself numerical, does not imply it cannot represent qualitative characteristics (see, e.g., Tabandeh et al. 2017). We evaluated these indicators at the parcel level, then analyzed them at two scales: the county level and the intermediate "neighborhood" level. Parcels are the smallest spatial units of land delineated in the study area (Fig. 1), with more than 18,000 discrete parcels across the entirety of Gulf County in 2019. Our second spatial scale of analysis, the neighborhood level (Fig. 1) is a grouping of census blocks around six neighborhoods of high-density residential properties. These neighborhoods were identified using a combination of (1) county zoning maps to narrow the geographic focus to residential zonings only, (2) visual identification of higher density residential areas using parcel data in ArcMap, and (3) the author's pre-knowledge of Gulf County and its distinct residential neighborhoods.

Housing losses were evaluated using the parcel-level property appraisal data from the Florida Tax Authority. Property appraisal data for 2018 and 2019 provide records of parcel value and land use and property type before and after Hurricane Michael. We confirmed with the state property appraiser that a parcel-by-parcel property impact survey was conducted and recorded after the storm, and that tax information contained in the property appraisal data is the most comprehensive measure of Hurricane Michael's immediate impact on residential properties. It is still quite possible the survey under-valued some property impacts due to the practical limitations of the post-storm valuation process (e.g., external observation vs. internal damages). The property appraisal data were made spatially explicit by joining them to the 2019 shapefile of county-wide parcel boundaries.

We analyzed all parcels in Gulf County categorized as residential in 2018. We included all parcels with any of the three residential base strata used by the Tax Authority (Table 1). We used the base strata to identifying the specific zoning of parcels as residential. We also observed the active strata to determine if parcels were actively being used for residential purposes. We then analyzed for 2019 the same parcels that were categorized as residential according to their 2018 base strata, which were identified in the 2019 data by the unique parcel identifier. Only those parcels whose unique identifier matched between the 2018 and 2019 appraisal data, as well as the 2019 shapefile, were retained. A total of 6731 residential parcels were analyzed for the entire county, but two were removed for block- and neighborhood-level analyses because of non-matching spatial data.

Monetary values of all residential parcels in 2018 and 2019 were obtained from the "just value" recorded in the property appraisal. We adjusted "just value" by the "just value change" also recorded in the appraisal data, which reflects any adjustment made to an initial property valuation upon a subsequent valuation. Monetary losses (or gains) were calculated for each parcel as the change in adjusted just value from 2018 to 2019. We then calculated these parcel-level losses (or gains) as a proportion of the 2018 


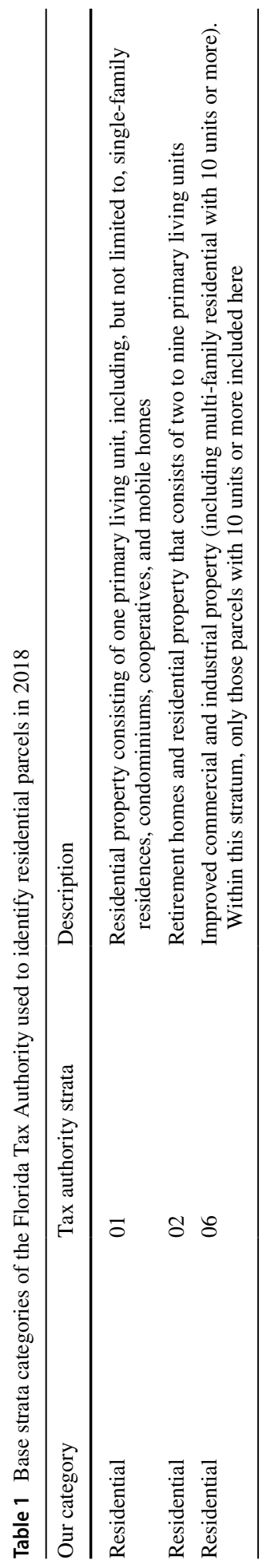


property value. One outlier was removed (parcel ID 03178-110R) whose 2018 just value change (from a second 2018 appraisal) reduced the parcel value by over $95 \%$, but the parcel's 2019 value was back to within $75 \%$ of the first 2018 appraisal. These changes could not meaningfully be in interpreted in relation to the storm impacts, and so this parcel was removed. Finally at the parcel level, we calculated the total number of residential units lost from 2018 to 2019 as the difference in total units within all parcels analyzed from 2018 to 2019.

Next, we aggregated parcel-level assessments to the census block level. We used the 2018 TIGER/Line shapefile (U.S. Census Bureau 2018) for census blocks and the 2019 parcel boundary shapefile to spatially join parcels to census blocks. The use of 2018 census blocks was to align with demographic statistical data during the year of the storm, while the use of 2019 parcels was to align with impacts experienced after the storm. We aggregated 2018-2019 changes in property value for all parcels within each block and in the total number of active residential units within each block. We then excluded all blocks with a net gain in parcel value from further analyses, in order to focus on the distribution of losses. A total of 463 blocks were analyzed further. The magnitude of monetary and housing capacity losses at the block level were then used in the calculation of neighborhood level impacts.

We compared how housing impacts from Hurricane Michael would be evaluated differently through the three indicators (absolute monetary losses, proportional monetary losses, housing capacity losses). We analyzed the rank-order of blocks according to each measure of losses because the absolute measures of monetary losses are extremely skewed. In this approach, blocks with a low rank for a particular impact indicator can be considered to have sustained smaller losses when compared to a block with a high rank through the same indicator. If the three indicators yield similar evaluations of impacts, one would expect the rank-order of blocks to lie close to the 1:1 diagonal when two indicators are plotted against each other. Large deviations from the expected 1:1 relationship (i.e., the residuals) indicate blocks where, for example, proportional value losses are much greater than total value losses, relative to other blocks, or vice versa.

Finally, we focused on the six neighborhoods (Fig. 1) in order to assess intermediate-level (i.e., broader than parcel/block-level but smaller than county-level) patterns in housing losses throughout the county. These include the two main cities of Port St. Joe and Wewahitchka, North Port St. Joe and "St. Joe Beach" (both distinct neighborhoods within greater Port St. Joe), as well as the unincorporated communities of Cape San Blas and Highland View. These areas are all zoned as residential, mixed commercial-residential or municipal. Within these zones, the neighborhoods were spatially bounded based on geographic proximity rather than formal municipal boundaries to maximize the number of parcels captured in the neighborhood analysis. Parcel-level impact statistics were aggregated within each of the neighborhoods. All statistical analyses were performed in $\mathrm{R}$ and all spatial data processing performed in ArcGIS. Additional informational sources were also collected to complement the primary analysis of housing data, including impact surveys conducted by academic, state and private institutions. One important note regarding the "St. Joe Beach" neighborhood is that it includes the newer subdivision of Beacon Hill, whose structures performed vastly differently from the older structures in St. Joe Beach (proper). These two localities could not be separated in our analysis because of the spatial boundaries of census blocks in this area, which spanned the two. 

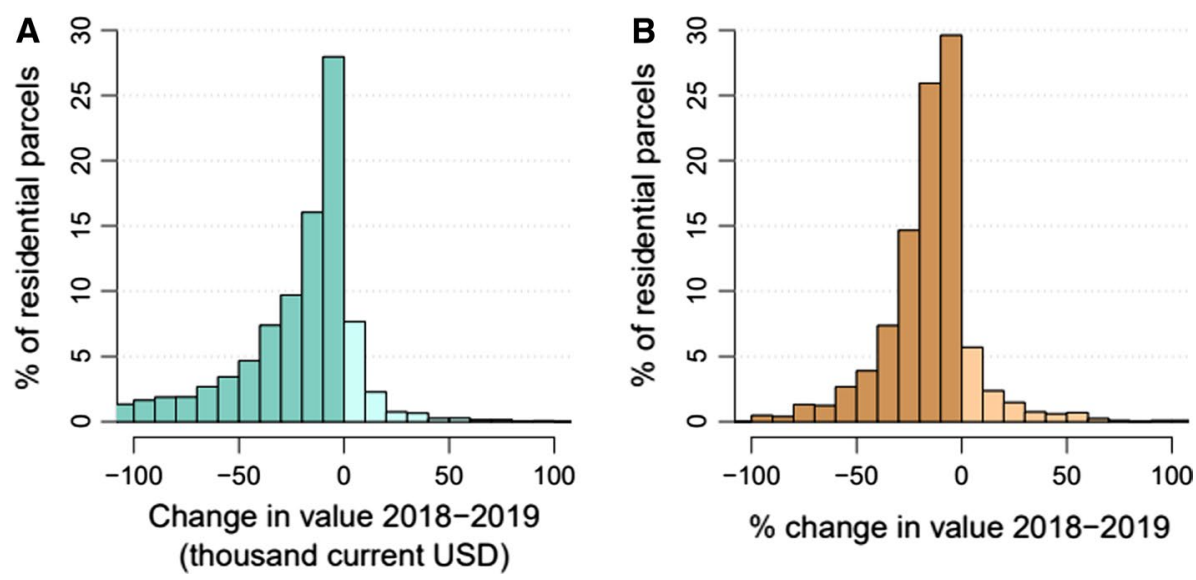

Fig. 2 Percent frequency distributions of (a) total and (b) percentage changes in value from 2018-2019 for 6731 Gulf County residential parcels. Darker color shades indicate parcels with monetary value losses. NB horizontal axes are truncated and actual ranges were \$-2.15 million to \$0.42 million for (a) and - 126 to $795 \%$ for (b), although only a tiny fraction of parcels had a change in value outside the ranges shown

\subsection{Wind speed analysis}

We analyzed the relationship between hurricane wind speeds and housing impacts using each of the three impact indicators. This analysis was performed at the neighborhood level by summarizing the three indicators for all parcels within each neighborhood: (1) average parcel value loss (in absolute monetary value); (2) average parcel value loss (as a percentage of 2018 value); and (3) percentage of residential units lost.

The three indicators for each neighborhood were then compared to average wind speeds for each neighborhood. Wind speeds were calculated using wind-field model data (see Vickery et al. 2006) provided as sustained wind speeds and three-second gust speeds at latitude and longitude coordinates across the study area. For each neighborhood, we took the average sustained and gust speeds for all lat/long points within a $1 \mathrm{~km}$ radius of the parcels within that neighborhood. Neighborhood average sustained wind speeds and average gust speeds were highly correlated, so we further analyzed only the former.

\section{Results}

\subsection{Parcel-level impacts}

Our analysis reveals that $85 \%$ of residential parcels in Gulf County sustained some degree of monetary value loss between 2018 and 2019. These gross monetary losses totaled more than $\$ 250$ million. Median property value in the county dropped by $19 \%$, from $\$ 139,400$ in 2018 to $\$ 112,500$ in 2019 . Almost $60 \%$ of residential parcels $(n=$ $4013)$ lost $\$ 10,000$ or more in value, while $6 \%(n=416)$ lost half of their 2018 value or more. Just over half of all properties lost between $\$ 1$ and $\$ 30,000$ in value (Fig. 2a) and two-thirds lost between 0 and $30 \%$ of their 2018 value (Fig. 2b). The largest absolute monetary loss sustained by a single property was $\$ 2.15$ million and six properties lost 

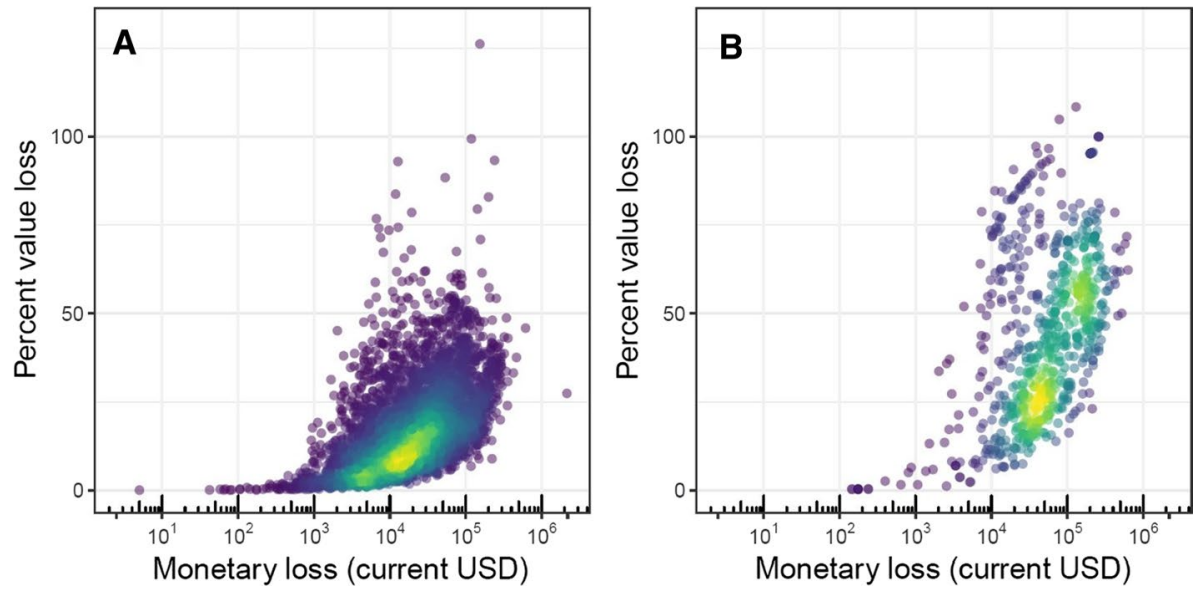

Fig. 3 Absolute monetary losses compared to percentage losses for (a) the 4892 residential parcels in Gulf County that experienced a monetary loss in value but remained active; and (b) the 776 residential parcels that experienced a monetary loss in value and became vacant. Points are colored by brightness according to increasing density in the plots

all of their value and more (i.e., by incurring a negative property value in 2019). Only $12 \%$ of properties gained value from 2018 to 2019 , and $3 \%$ did not change in value.

In terms of housing capacity lost, our analysis shows that $17 \%$ of active residential units $(n=1186)$ were lost following Hurricane Michael, which mirrors the dramatic drop in Gulf County's population of over $15 \%$ in the same period (U.S. Census Bureau, n.d.). These losses include 194 active units that became vacant from 2018 to 2019, as well as 992 units active in 2018 that disappeared in 2019. Additionally, loss of residential units does not imply a monetary loss in property value from 2018 to 2019 (e.g., if a multi-unit property was converted to a single-unit property with greater value). However, our qualitative assessment suggests the actual impact to housing capacity is much higher when considering some residential units are still occupied but in squalid condition due to storm damage.

Our analysis of the 5668 residential parcels that suffered monetary loss in value revealed that many properties sustaining very high proportional losses remained active residences (Fig. 3a). Of the 413 parcels that lost more than half of their value from 2018 to 2019,84 remained active residential in 2019, including 10 properties that lost more than $75 \%$ of their value (Fig. 3a), indicating that some residents in Gulf County are living in properties worth only a fraction of their pre-hurricane value. When visiting Gulf County in March 2020, Boda observed the continued widespread use of plastic tarps and other temporary fixes to residential properties in, for example, (North) Port St. Joe and Highland Views. In other locations, such as St. Joe Beach, large portions of the coastal residential areas remain cleared, with only concrete foundations remaining of the properties destroyed in Hurricane Michael. The vast majority (91\%) of parcels that lost value and became vacant in 2019 sustained losses of more than $\$ 10,000$ (Fig. 3b), yet almost a quarter of vacancies occurred with losses less than $25 \%$ of their 2018 value and as little as $0.3 \%$ (Fig. 3b), perhaps indicating residents who relocated after the storm without having personally sustained significant property impacts. 


\subsection{Neighborhood-level impacts}

Neighborhoods differed greatly in terms of total value, proportional value and housing capacity impacts (Table 2). Net parcel losses across neighborhoods range from \$1.2 million (Highland View) to $\$ 68$ million (Cape San Blas), while proportional losses across neighborhoods ranged from $7 \%$ in Highland View to $24 \%$ in St. Joe Beach. Average change in parcel value had a wide range from almost $\$ 4,677$ in North Port St. Joe to almost $\$ 75,000$ in Cape San Blas. Average proportional change in parcel value ranged between 1 and $22 \%$. Residential unit losses ranged from $6 \%$ of the housing units in Port St. Joe to $30 \%$ in St. Joe Beach. St. Joe Beach and Highland View sustained by far the highest percentage loss of housing units of all neighborhoods.

\subsection{Differences among indicators}

Our results show that the three indicators used give very different pictures as to the distribution and magnitude of impacts. If the three indicators were to give equivalent evaluations of impacts, one would expect the rank-order to be similar when assessed through each indicator, which is not the case in Gulf County (Fig. 4). Large monetary losses do not necessarily imply large proportional losses or losses in housing capacity (i.e., percent of units lost within a block), and vice versa.

The uneven distribution of impacts throughout Gulf County become even clearer when comparatively ranking the six neighborhoods along the three impact indicators used (Fig. 4). High value properties in Cape San Blas dominate the monetary loss rankings, while less than $10 \%$ of housing units were lost in this neighborhood (Table 2). In contrast, Highland View sustained comparatively low monetary losses per parcel overall, but had massive losses of housing units. North Port St. Joe and Wewahitchka are clustered largely in the upper left corner of Fig. 5a and c, implying that, while the total monetary losses in these communities was relatively little in comparison to other neighborhoods, e.g. Cape San Blas, they still experienced devastating impacts to property, as reflected in high proportional loss rankings (Fig. 4c), and/or in direct housing capacity, as reflected in high percent unit losses (Fig. 4a). Certain neighborhoods, such as Port St. Joe and St. Joe Beach, show a distribution indicative of high housing capacity losses across parcels that sustained all levels of total or proportional monetary losses (Fig. 4a and b). Port St. Joe and St. Joe Beach also show a less skewed relation between total loss rankings and percent loss rankings than lower-income parts of the county; e.g., North Port St. Joe and Wewahitchka (Fig. 4c).

\subsection{Housing impact association with wind speed}

In general, the percentage of residential units lost per neighborhood increases with wind speeds (Fig. 5). St. Joe beach and Port St. Joe, respectively, had the highest and lowest wind speeds and percentage of residential units lost. The exception to the general trend is Wewahitchka, which had a relatively low percentage of residential units lost relative to the high wind speeds.

Similarly, the average percentage of parcel value lost generally increases with wind speeds, but to a lesser extent than residential unit losses (Fig. 5). The exception is Highland View, which had an average percentage parcel value change close to zero despite 


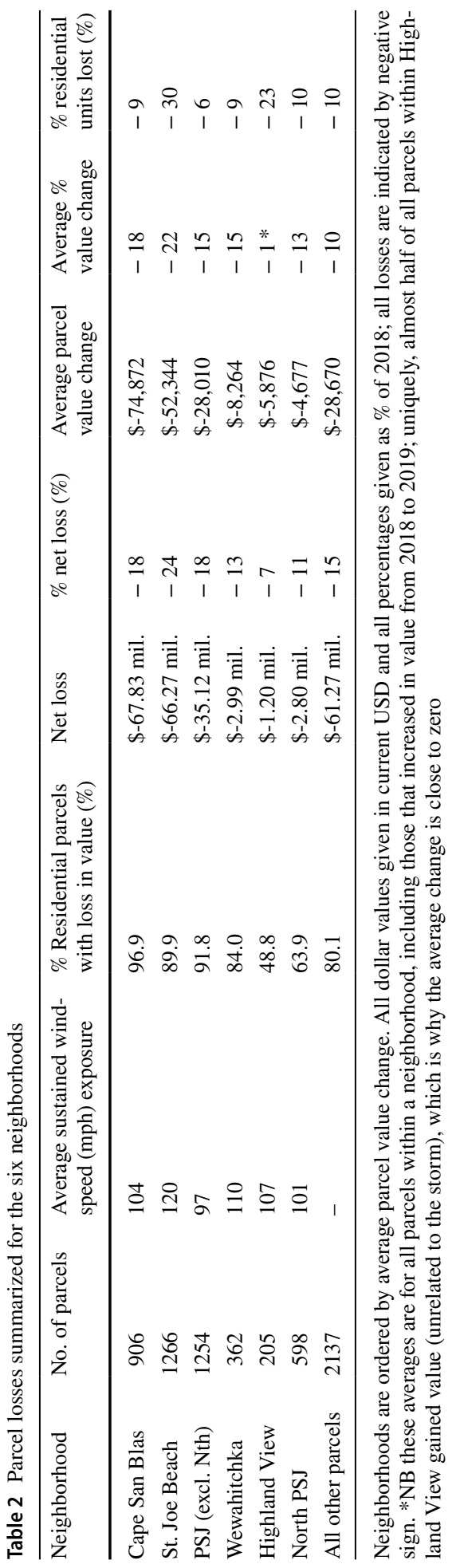



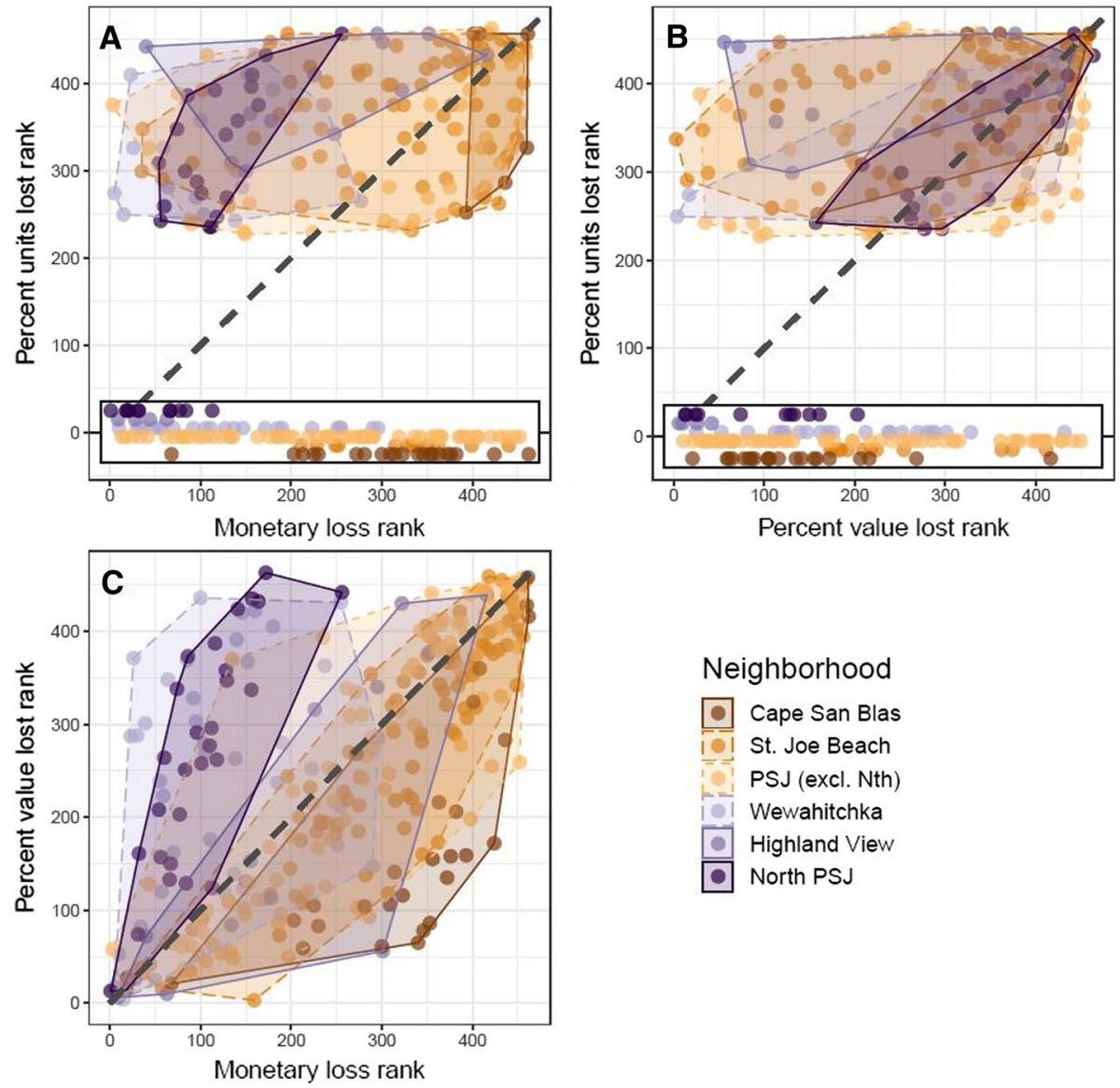

Neighborhood

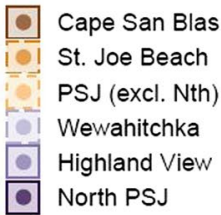

Fig. 4 Comparison of the three impact indicators used to evaluate aggregated census block losses for the six neighborhoods. a Comparison of rank orders of census blocks by absolute monetary losses ( $x$ axis) and housing capacity losses ( $y$ axis). b Comparison of rank orders of census blocks by proportional monetary losses ( $x$ axis) and housing capacity losses ( $y$ axis). c Comparison of rank orders of census blocks by absolute monetary losses ( $x$ axis) and proportional monetary losses ( $y$ axis). Boxes along zero in panels a and b indicate those census blocks with no housing unit losses. Port St. Joe abbreviated to PSJ in legend. NB census blocks outside the six neighborhoods shown in gray in Fig. 1 are excluded here

experiencing the third highest wind speeds of the six neighborhoods. This can be explained, at least in part, by the fact that almost half of the residential parcels within Highland View actually increased in value from 2018 to 2019 (seemingly unrelated to the storm), which resulted in the average percentage parcel value change being close to zero.

For the absolute parcel value lost, no trend is apparent with wind speed (Fig. 5). Cape San Blas clearly suffered the highest absolute value losses but wind speeds in this neighborhood were toward the lower end of the range. North Port St. Joe, Highland View and Wewahitchka all had relatively low absolute value losses despite a range of wind speeds experienced. 


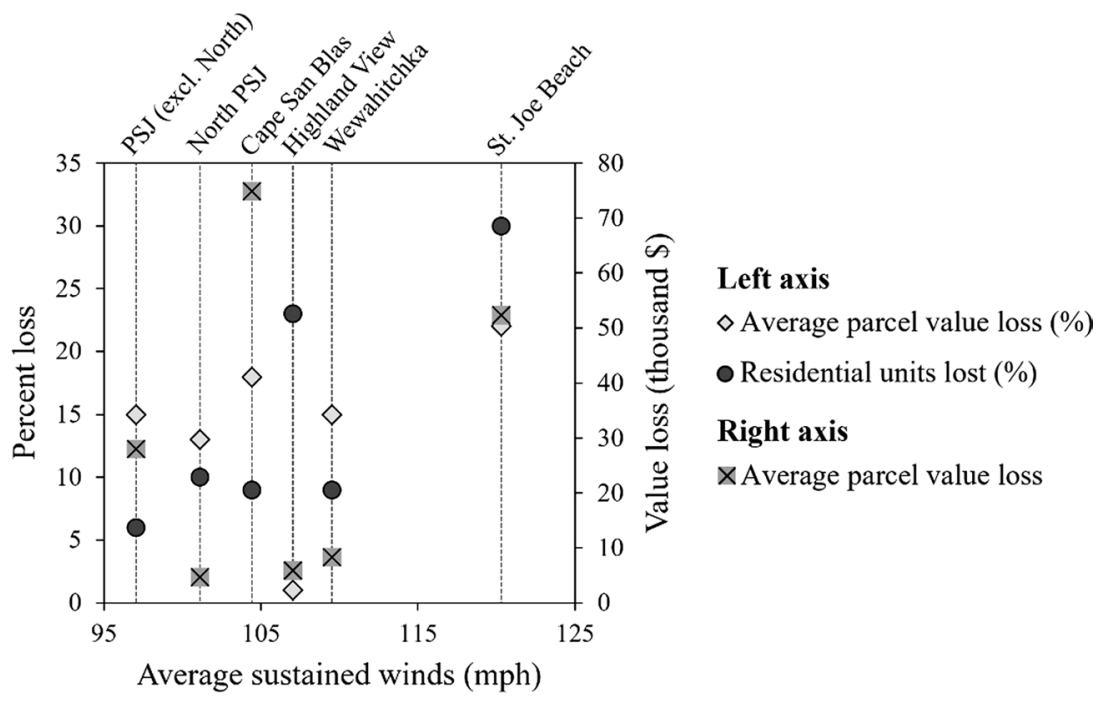

Fig. 5 Average sustained wind speeds compared to the three impact indicators for each neighborhood

\section{Discussion}

\subsection{Housing impacts from the perspective of capital theory}

Capital Theory approaches sustainable development from a utilitarian perspective and aims to sustain aggregate social utility overtime, generally measured using per capita income as an indicator of productive capital stock. It thus emphasizes that sustainable development is development that maintains a society's overall productive capacity (i.e., stock of productive capital), as this is considered the driver of economic growth and the source of utility (Solow 1991). Monetary metrics and cost-benefit analysis are necessary tools used to monitor and evaluate capital growth over time. Some have criticized the use of monetary metrics and CBA in particular in evaluating social progress and programs, pointing to its propensity to be inaccurate, exclusionary and negligent of the question of distribution (e.g. Rose-Ackerman 2010). Despite such criticisms, this approach remains by far the most dominant in climate-related environmental and social impact assessment and policy evaluation (Boda et al. 2021; McNamara and Jackson 2019). From this perspective, housing is understood primarily as a "stock of capital" that is one among many factors contributing to economic productivity. As a result, the most relevant information for understanding Hurricane Michael's impacts to housing in Gulf County from the Capital Theory perspective is to focus on the more than $\$ 250$ million in county-wide aggregate property value losses, as these represent the aggregate, immediate capital stock impacts from the storm. When it comes to the disproportionate distribution of these impacts, and thus the identification of "high impact" areas within the county, the focus will be on those areas with the highest property value losses. In other words, the most impacted areas from the perspective of Capital Theory are those with the largest quantity of monetary value lost.

Cape San Blas and St. Joe Beach show up as the first and second most impacted neighborhoods with $\$ 67.83$ and $\$ 66.27$ million in losses, respectively. Their collective impacts amount to just over half (54\%) of the total losses county-wide, while accounting 
for only $33 \%$ of county-wide residential parcels. The impact in these neighborhoods, as measured in total monetary losses, is nearly double the amount of the next most impacted neighborhood, namely Port St. Joe. Other neighborhoods were ranked comparatively much lower in terms of magnitude of impacts due to their more marginal importance for overall housing stock value. This includes, for example, the entire neighborhoods of Wewahitchka, North Port St. Joe and Highland View, which sustained \$2.99, $\$ 2.8$ and $\$ 1.2$ million net losses, respectively. When combined, these three neighborhoods amount to a total of $\$ 7$ million in losses, or a mere $3 \%$ of county-wide losses, while accounting for $17 \%$ of county-wide residential parcels.

With its focus on aggregate monetary losses, the other analytical indicators we used to assess impacts on housing in Gulf County, i.e., percent value loss and housing capacity loss, are less relevant from the perspective of Capital Theory, as they reflect qualitative differences in housing impact severity rather than total measures of capital value losses. The focus on aggregate monetary losses is justified by the assumption in Capital Theory that capital stocks are substitutable, so restoring the lost capital stock represented by the total housing value losses may be theoretically accomplished by other means than rebuilding or restoring housing itself, for example investment in a different productive industry. While the distribution of county-wide housing value losses is demonstrably highly uneven, it should be noted that, while Capital Theory is not concerned with the precise distribution of capital in society, it is not completely negligent of the issue. Rather, Capital Theory relies on the assumption that a well-functioning market economy will provide the most efficient and effective mechanism for distributing aggregate social wealth derived from capital stock within society (Solow 1989).

One pertinent question to ask regarding the cause of these aggregate monetary losses is why the total loss values are much higher in some neighborhoods than others. One reasonable assumption would be that areas that experienced the most exposure to extreme wind speeds and storm surge also experienced the most severe impacts, and this would be captured in the quantity of monetary losses. However, if we look at the correlation between wind speed exposure and total monetary losses across Gulf County (Fig. 5), we find a slight negative correlation, meaning the average total monetary losses at the parcel level tended to go down as wind speed exposure increases. This is largely due to the dominance of Cape San Blas in this indicator, which received by far the highest average total monetary loss per residential parcel with wind speed exposure toward the lower end of the spectrum (Table 2). Cape San Blas is located on a sand spit, and thus highly exposed to potential storm surge impacts, which likely increased impacts (e.g. property erosion) in this area in addition to wind speed impacts. Still, other neighborhoods which experienced both higher wind speeds and more severe beacon impacts (e.g., St. Joe Beach) still ended up with lower total monetary losses than Cape San Blas. This points to one very important factor underlying the quantity of monetary losses measured, namely the original value of the housing stock in each neighborhood. More expensive houses will always cost more to repair than lower cost houses when they experience the same severity of impacts, and indeed less expensive houses may experience extremely severe impacts and not even come close to measuring up to the total monetary costs of minor impacts of high-priced homes. In this way, the focus on total monetary losses has the potential to overshadow severely impacted neighborhoods which simply do not have the property values to compete with wealthier parts of the county. While the focus on total monetary losses may in some instances provide a useful reference for the severity of impact in a neighborhood, for example St. Joe Beach, it at the same time may give the 
inaccurate impression that neighborhoods with lower levels of total monetary losses are less severely impacted, when this may not be the case empirically.

Another factor that may contribute to skewed distribution of total monetary losses is the construction standards of individual houses. Prevatt and Roueche (2019) for example, in their post-disaster assessment, suggest that disproportionate impacts at the parcel level result from a combination of hazard exposure and, importantly, housing construction standards, material quality and building age. The authors note, for example, "an interesting trend demonstrated in the data [on wind-speed damage], the non-progressive nature of the wind speed to damage relationship. Generally, it is expected that wind damage increases with wind speed, all else being equal. In this case, design wind speeds for the majority of the study region are nearly the same, negating that possible factor. It is unexpected then to see the average wind damage rating actually decrease for homes that experienced the highest wind speeds, relative to those that experienced the lowest or middle tier wind speed range. Further research into this trend is warranted, potentially with detailed review of permit records where available. It is possible that newer homes in the coastal areas that experienced higher wind speeds were more likely to invest in code-plus construction." (p. 26). Note that the scale used to assess damage severity by Prevatt and Roueche (2019) was not monetary losses, but a "damage rating" system adopted from Vickery et al. (2006), which documents and quantifies observable structural damage by percent, which is then assigned a severity ranking ranging from "no observable damage" to "destruction." These findings show that even in instances of higher exposure, home owners who can afford additional safety standards when constructing their house may be able to minimize or avoid degrees of impact that other homeowners living in housing with lesser construction design standards cannot. This again points to the advantages afforded to wealthy residents in Capital Theory-based post-disaster assessment and recovery. On one side, they are more capable of mitigating impacts by building homes with additional safety features, while also being prioritized in impact assessment due to the high value of their homes. Lower income residents, on the other hand, cannot mitigate impacts and are undervalued in assessment due to their relatively lower property values.

Capital Theory offers little insight into how to deal with such qualitative disproportionality in impacts. Its propensity to focus on more expensive (even if less severe) impacts to high value properties also means it tends to overlook, or at least underemphasize, cases of proportionally equal or even more severely impacted properties if these are relatively low in monetary value. This is exemplified clearly when comparing North Port St. Joe and Cape San Blas - Cape San Blas experienced higher wind speeds on average and recorded very high total monetary losses, but these amounted to a similar degree of qualitative impact (as measured in percent value losses, see Table 2) to North Port St. Joe, even though North Port St. Joe experienced lower wind-speeds on average and recorded only a small fraction of the total monetary losses compared to Cape San Blas. This is likely due to the differences in housing quality/construction standards and demonstrates that the focus on total monetary losses may highly obscure the differences in the severity of impacts to residential properties across Gulf County.

\subsection{Housing impacts from the perspective of capabilities approach}

The Capabilities approach conceptualizes sustainable development from a non-utilitarian position, focusing on addressing objective deprivations in contrast to maximizing aggregate social utility measured in monetary units. Sustainable development is thus 
viewed as the process by which individuals are empowered to pursue lives they have reason to value, rather than as the process of capital accumulation (see Sen 2001). The freedom of individuals to live meaningful lives is a factor of a person's capability set, that is, the substantive opportunities available to the person. Free persons can combine their different capabilities to achieve different functioning states (i.e., different lifestyles). Sustainable development, from this perspective, aims to expand peoples' substantive opportunities (capabilities) to live valuable lives, and it draws on a wide variety of indicators to monitor and evaluate the gains and losses to capabilities.

From this perspective, housing is understood primarily as a basic necessity (often called a "conversion factor") for a wide variety of essential capabilities, including maintaining health and employment. Interpreting housing impacts in this perspective implies understanding them as leading to the deprivation of individual capabilities, as a lost or otherwise severely impacted home can significantly affect a person's ability to live a healthy, secure, and otherwise meaningful life. The most relevant information, then, is not the aggregate monetary losses as in Capital Theory, but the disaggregated impacts that indicate losses or gains to individual capabilities. Thus, the most pertinent information is regarding the qualitative severity of impacts to a particular residential property/neighborhood (e.g., proportional value losses), as well as the over-all capacity to accommodate citizens with residential units (e.g., housing capacity losses). For example, a cheap home which lost its roof in the storm may not be register high on the total monetary loss indicator, but the severity of these impacts will be reflected in the proportion of the houses value lost due to the impacts, or whether the residential property was deemed unlivable (and thus useless as a capability enhancing asset). It should be noted that an interest in disproportionality in qualitative impacts, however, does not preclude the possibility of assessing these impacts using quantitative data, as we have done here via e.g. proportional value losses. When it comes to the disproportionate distribution of impacts, the capabilities approach aims to focus on those residents who are the least well off, recognizing that there are qualitatively different kinds of capability deprivation connected to pre-existing inequalities in capability sets and functioning achievements (Gardoni and Murphy 2009), including, for example, differences in housing quality and construction standards.

Our results (Table 2) reveal that impacts viewed through the lens of proportional monetary losses show a very different distribution of impacts across neighborhoods compared to the Capital Theory approach. From this perspective, highly impacted areas under Capital Theory approach show up again as highly impacted, though their relative impacts are rendered more comparable to other neighborhoods. Average percent value losses ranged from $22 \%$ in St. Joe Beach, to $13 \%$ in North Port St. Joe, signifying a much more reasonable spread of impact severity across the county when compared to the spread under Capital Theory. Percent residential units lost also indicates a different distribution in impact severity across the neighborhoods, with losses ranging from $30 \%$ in St. Joe Beach to $6 \%$ in Port St. Joe. The use of these qualitative impact indicators helps to correct for the distortions in distribution caused by a focus on total monetary value and thus to highlight highly impacted neighborhoods independent of their original property values. For example, Wewahitchka had an average residential parcel percent value loss of $15 \%$. This is the exact same value as Port St. Joe (excl. Nth), implying comparable levels of impact severity in these neighborhoods. However, these two neighborhoods were magnitudes apart in terms of total monetary losses (\$2.99 vs. \$35.12 million, respectively), implying Port St. Joe was much more impacted than Wewahitchka. In fact, Wewahitchka lost more residential units than Port St. Joe, even at the same level of proportional value loss. 
In contrast to Capital Theory, the capabilities approach requires the disaggregation of impacts in order to more accurately assess the implications of housing impacts on individual capabilities, and thus, it draws on indicators capable of reflecting qualitative differences in impact, rather than only quantitative magnitudes. This implies that the capability approach, unlike the Capital Theory approach, provides means to more accurately assess the objective deprivation resulting after an extreme event like Hurricane Michael regardless of the socioeconomic status of the residents in the area. However, the capabilities approach, again unlike Capital Theory, is necessarily concerned with pre-existing capabilities and how these mediate the experience of a disaster, for example the degree of poverty (and thus capacity for recovery) in a particular community. The impact indicators we utilized in this study, specifically the proportional value losses and housing capacity losses within neighborhoods, could be enriched with additional socioeconomic and demographic data that would allow practitioners to identify areas of high impact that may also suffer from other disadvantages, for example the relatively high level of poverty in the county. These areas could potentially represent hot spots of deprivation which would require special attention in the short- and long-term recovery process.

\subsection{Relative (dis-)advantages of each approach}

Capital Theory comes with inter alia strong technical advantages. One of the most immediate is that it is the appropriate fit for much of the current practice in the areas of DRR, $\mathrm{CC}$ adaptation and loss and damage, where economic-based assessment and policy rules the game (McNamara and Jackson 2019; Boda et al. 2021). In this way, it at very least offers an operational and systematic approach to assessing impacts from climate-related extreme events. The approach is also comprehensive though reductionist, meaning Capital Theory has a strategy for incorporating all types of impacts during assessment, but this requires that all relevant impacts first be converted into monetary terms. Politically speaking, Capital Theory's focus on economic concepts, metrics and financial risk reduction policies results in a degree of relative clarity and decisiveness that some argue may be essential for operationalizing climate-impact research in the existing political climate (Roberts et al. 2017), or including "stakeholders" such as the private sector (Surminski and Eldridge 2015). Historically, the kind of strict reductionism inherent in Capital Theory has proven appealing to policymakers in relation to a wide variety of environmental and development concerns (Porter 1996), and the monetization of impacts may be necessary in some cases for purposes of resource redistribution or compensation in the recovery process. Capital Theory in short offers a coherent, comprehensive and integrative approach to assessing impacts from climate-related extreme events by focusing on impacts to total capital stock and measuring these impacts in monetary terms. There are however several serious disadvantages to the Capital Theory approach. One is that its focus on aggregate monetary losses has the potential to draw attention away from some severely impacted areas simply because they do not have an adequate amount of property wealth to register as "high impact." For example, it is practically impossible for low property value neighborhoods like North Port St. Joe (average parcel loss of \$4,677), which experienced levels of proportional value losses comparable with many other neighborhoods, to be identified as the "most impacted" area under this perspective, as they simply do not have the property wealth to compare quantitatively with places like Cape San Blas (average parcel loss of $\$ 74,872)$. This has clear implications for equity and fairness in accounting for impacts and 
prioritizing recovery, where studies have shown that an over-emphasis on regaining property value can lead to a deepening of pre-existing inequalities (Peacock et al. 2014; Zhang and Peacock 2009).

On the other hand, the capabilities approach, as we see it, has several distinct advantages over Capital Theory. While Capital Theory is primarily concerned with aggregate monetary losses and must convert all relevant impacts into this unitary metric, the capabilities approach does not ignore the importance of monetary losses, but incorporates it as one relative factor potentially affecting capabilities. That is to say, one should take note of monetary losses not in its absolute magnitude (á la Capital Theory), but in terms of the contribution that this magnitude makes relative to the overall human capabilities of its proprietor. Relative figures such as proportional losses are instead preferred as they allow some meaningful comparability between lower property value areas like North Port St. Joe and high property value ones like Cape San Blas in terms of qualitative severity of impacts. This is because the capabilities approach is concerned with the lost use-value of property, not only the exchange value. The importance of recognizing the qualitative difference between total and proportional impacts, and their implications for low-income households, has been noted by other climate-impact researchers as well (van der Geest 2018). The capabilities approach's interest in the qualities of impacts allows for the inclusion of all properties, irrespective of property value, that experienced severe immediate impacts, and in this sense, it is significantly less likely to unduly emphasize select (wealthy) areas over others. Clearly, some neighborhoods with very high total monetary losses also experienced very high proportional losses and housing stock losses. This is the case for example with St. Joe Beach (located adjacent to Mexico Beach in Bay County), which ranks highly in terms of impact severity in both Capital Theory and the capabilities approach, as it not only has many high-value properties, but was ground zero where Hurricane Michael made landfall, and thus experienced near complete devastation from wind and storm surge. Clearly, this neighborhood was severely impacted by practically any standard, and the fact that many of the residents in this neighborhood may be wealthy does not detract from the significance of their situation after the storm. At the same time, other neighborhoods which would hardly registered on a Capital Theory list of "most impacted," such as North Port St. Joe or Wewahitchka, can be shown through the capabilities approach to have in fact sustained severe impacts comparable to other neighborhoods with much higher levels of total monetary losses (e.g. Cape San Blas).

Of course, there are many important capabilities not well captured by the kind of valuefocused housing impacts we analyzed here, which might reasonably be expected in the aftermath of any extreme event. These include, for example, access to adequate nutrition, environmental quality concerns, or loss of community belonging, which affect many of the most vulnerable people including homeless, people with disabilities, children, elderly and low-income renters. These kinds of so-called non-economic impacts have been much discussed in research on the impacts from anthropogenic climate change, particularly in loss and damage circles. One of the main bones of contention regards what metrics are appropriate when accounting for non-monetary impacts. Some argue non-economic or intangible impacts from $\mathrm{CC}$ cannot or should not be quantified or made comparable due to their being derived from particular cultural and geographical contexts, which renders them incommensurable (Tschakert et al. 2017). As we have seen, the answer to this question from within Capital Theory is to simply require all relevant impacts be converted into monetary metrics, thus rendering them commensurable (Dilley and Grasso 2016), for which there are many standard tools (Preston 2017). However, a focus on capabilities does not necessitate or preclude quantification, nor require the use of any unitary metric, but rather 
draws on a dashboard of relevant indicators. The use of such an indicator dashboard is quite different from the elaboration of extensive lists of qualitatively different and presumably incommensurate impacts from CC (cf. Tschakert et al. 2019; also see the "wish-list" literature from Boda et al. 2021). Under the capabilities approach, the incommensurability of the varying kinds of possible impacts from climate-related events is accepted, but unity among diversity is not achieved via a unitary metric (such as money in the Capital Theory approach). Rather, the possibility of comparing the wide variety of qualitatively different possible impacts from $\mathrm{CC}$ is achieved through a unitary concept (i.e., capabilities) which coherently expresses relations among these varying kinds of impacts and their implications for peoples' substantive freedoms and well-being (see Sen 2001, Ch. 1). In this way, the capabilities approach also offers a coherent, comprehensive and integrative approach to assessing climate-related extreme events, with some important advantages over Capital Theory in terms of its focus on the least-well-off, its openness to a wide variety of information beyond monetary value and its relative fairness in representation across different areas of impact.

It is here that we note perhaps the most significant challenge for a capabilities approach to climate-related impact studies, in contrast to the merits of Capital Theory; namely, the difficulty of operationalizing a capabilities approach in actual sustainable development practice. One relative advantage of the Capital Theory approach is its imminent compatibility with current practice; this however is not the case with the capabilities approach. Indeed, much current practice would need to change significantly if a capabilities approach were to be operational in practice, for example the legal obligation (in the USA) for many public agencies to abide by rules of cost-benefit analysis in social and environmental policy evaluation. Disaster impact databases, which tend to prioritize aggregate measurements of monetary impact, would likewise need to expand the kinds of information and impact indicators used to assess impacts from climate-related extreme events around the world. Ideally, the indicators included in such a dashboard should reflect a set of contextually relevant capabilities, and the prioritization of these capabilities should, within the realm of reasonable possibility, be set through a process of open and reasoned public deliberation (see Sen 1999). While his attempt to operationalize the capabilities approach lead Sen into the realm of ethics and theories of justice (see Sen 2011), there are unquestionably other avenues open for exploration regarding how to feasibly implement a capabilities approach, which points toward fruitful further research, in particular investigating the connection between disaster impact assessment and processes of social and political change.

\section{Conclusions}

In this article, we have provided empirical measurements of impacts to residential properties in Gulf County, Florida, occurring from Hurricane Michael, a climate-related extreme event. In the aggregate, we reported widespread and devastating impacts, with nearly nine in ten county-wide residential properties sustaining immediate value losses, and nearly 1 in 5 of total residential units rendered vacant or lost between 2018 and 2019. Our interpretation of these impacts through two different theories of sustainable development show that the theory adopted to analyze impacts can lead to dramatically different appraisals of where and whom is considered "most impacted." Capital Theory offers a coherent and operational means for consistently measuring impacts to capital stocks, but also tends to emphasize expensive property impacts rather than severe property impacts. The capabilities approach 
provides a means for disaggregating impacts and highlighting those areas with the most severe impacts, but its informational requirements make it incompatible with much current practice. In terms of social justice, equity and who bears the brunt of impacts from natural hazards, our analysis of the Capital Theory approach demonstrates that, within this approach, the losses that people in poorer neighborhoods suffer are generally going to be drowned out by the figures from wealthier neighborhoods. In contrast, our analysis of the capability approach shows that this perspective draws attention to those residents least able to absorb and recover from the impacts of an extreme event, which often bear the brunt disproportionately large. We thus conclude that the capability approach is much less likely to lead researchers and practitioners to overlook the most disadvantaged communities when compared to Capital Theory.

Funding Open access funding provided by Lund University. Swedish National Research Council (FORMAS), project 2018/0010 "Recasting the disproportionate impacts of climate change extremes (DICE)".

Availability of data and material: Data available upon request from corresponding author

Code availability Code available upon request from corresponding author.

\section{Declarations}

Conflict of interest The author declares that they have no conflict of interest.

Open Access This article is licensed under a Creative Commons Attribution 4.0 International License, which permits use, sharing, adaptation, distribution and reproduction in any medium or format, as long as you give appropriate credit to the original author(s) and the source, provide a link to the Creative Commons licence, and indicate if changes were made. The images or other third party material in this article are included in the article's Creative Commons licence, unless indicated otherwise in a credit line to the material. If material is not included in the article's Creative Commons licence and your intended use is not permitted by statutory regulation or exceeds the permitted use, you will need to obtain permission directly from the copyright holder. To view a copy of this licence, visit http://creativecommons.org/licenses/by/4.0/.

\section{References}

Avila LA (2019) The 2018 Atlantic hurricane season: another catastrophic year for the United States. Weatherwise 72(4):14-21. https://doi.org/10.1080/00431672.2019.1612201

Barnett J, Tschakert P, Head L, Adger WN (2016) A science of loss. Nat Clim Chang 6:976

Beven JL, Berg R, Hagen A (2018) National hurricane center tropical cyclone report: hurricane michael (AL142018)

Boda CS (2018) The entrepreneurial sunshine state: neoliberalism, growth management and environmental conservation in Florida. J Urban Aff 40(6):838-862. https://doi.org/10.1080/07352166.2017.1413287

Boda CS, Faran T, Scown M, Dorkenoo K, Chaffin BC, Nastar M, Boyd E (2021) Loss and damage from climate change and implicit assumptions of sustainable development. Clim Change 164:13

Boda CS, Jerneck A (2019) Enabling local adaptation to climate change: towards collective action in Flagler Beach, Florida, USA. Clim Change 157:631-649. https://doi.org/10.1007/s10584-019-02611-6

Boda CS, Scown M, Faran T, Nastar M, Dorkenoo K, Chaffin BC, Boyd E (2020) Framing Loss and Damage from climate change as the failure of Sustainable Development. Climate Dev. https://doi.org/10.1080/ 17565529.2020.1851640

Comerio MC (1997) Housing issues after disasters. J Conting Crisis Manag 5(3):166-178. https://doi.org/10. $1111 / 1468-5973.00052$

Dilley M, Grasso VF (2016) Disaster reduction, loss and damage data, and the post-2015 international policy agenda. Environ Sci Policy 61:74-76. https://doi.org/10.1016/j.envsci.2016.04

FDACS (2018) Hurricane Michael's damage to Florida agriculture. Florida department of agriculture and consumer services 
Gardoni P, Murphy C (2008) Recovery from natural and man-made disasters as capabilities restoration and enhancement. Int J Sustain Dev Plann 3(4):317-333

Gardoni P, Murphy C (2009) Capabilities-based approach to measuring the societal impacts of natural and manmade hazards in risk analysis. Nat Hazards Rev 10(2):29-37

Gardoni P, Murphy C (2010) Gauging the societal impacts of natural disasters using a capability approach. Disasters 34(3):619-636

Greig A, Hulme D, Turner M (2007) "Challenging global inequality: development theory and practice in the 21st century". Palgrave Macmillan

IPCC (2018) An IPCC special report on the impacts of global warming of $1.5^{\circ} \mathrm{C}$ above pre-industrial levels and related global greenhouse gas emission pathways. Intergovernmental Panel on Climate Change (IPCC)

McNamara KE, Jackson G (2019) Loss and damage: a review of the literature and directions for future research. WIREs Clim Change. https://doi.org/10.1002/wcc.564

NOAA (2020) U.S. Billion-dollar Weather and Climate Disasters, 1980 - present (NCEI Accession 0209268). Retrieved June 12, 2020, from https://data.nodc.noaa.gov/cgi-bin/iso?id=gov.noaa.nodc:0209268

Otto FEL, Harrington LJ, Frame D, Boyd E, Cedervalle Lauta K, Wehner M, Clarke B, Raju E, Boda C, Hauser M, James RA, Jones RG (2020) Towards an inventory of the impacts of human-induced climate change. Bull Am Meteor Soc 101:E1972-E1979 (BAMS-D-20-0027.1)

Patricola CM, Wehner MF (2018) Anthropogenic influences on major tropical cyclone events. Nature 563(7731):339-346. https://doi.org/10.1038/s41586-018-0673-2

Peacock WG, Van Zandt S, Zhang Y, Highfield WE (2014) Inequities in long-term housing recovery after disasters. J Am Plann Assoc 80(4):356-371. https://doi.org/10.1080/01944363.2014.980440

Porter TM (1996) Trust in numbers: the pursuit of objectivity in science and public life. Princeton University Press

Preston CJ (2017) Challenges and opportunities for understanding non-economic loss and damage. Ethics Policy Environ 20:143-155

Prevatt DO, Roueche DB (2019) Survey and investigation of buildings damaged by category-III, IV \& V Hurricanes in FY 2018-2019 - Hurricane Michael. Project \#P0091032

Roberts JT, Natson S, Hoffmeister V, Durand A, Weikmans R, Gewirtzman J, Huq S (2017) How will we pay for loss and damage? Ethics Policy Environ 20(2):208-226

Rose-Ackerman S (2010) Putting cost-benefit analysis in its place: rethinking regulatory review. Univ Miami Law Rev 65:335

Sen A (1999) The possibility of social choice. Am Econ Rev 89(3):349-378. https://doi.org/10.1257/aer.89.3. 349

Sen A (2001) Development as freedom. Oxford Paperbacks

Sen A (2011) The idea of justice. Harvard University Press

Serdeczny OM, Bauer S, Huq S (2018) Non-economic losses from climate change: opportunities for policyoriented research. Clim Dev 10(2):97-101

Solow RM (1986) On the intergenerational allocation of natural resources. Scand J Econ 88:1

Solow RM (1991) Sustainability: an economist's perspective. The eighteenth J. Seward Johnson lecture. Woods Hole Oceanographic Institution, Woods Hole, MA

Surminski S, Eldridge J (2015) Observations on the role of the private sector in the UNFCCC's loss and damage from climate change work program. Int J Global Warm 8:213-230

Tabandeh A, Gardoni P, Murphy C (2017), A reliability-based capability approach. Risk Anal. 38(2)

Thomas A, Serdeczny O, Pringle P (2020) Loss and damage research for the global stocktake. Nat Clim Chang. https://doi.org/10.1038/s41558-020-0807-Z

Ton KT, Gaillard JC, Adamson C et al (2020) An empirical exploration of the capabilities of people with disabilities in coping with disasters. Int J Disaster Risk Sci 11:602-614. https://doi.org/10.1007/ s13753-020-00287-6

Tschakert P, Ellis NR, Anderson C, Kelly A, Obeng J (2019) One thousand ways to experience loss: a systematic analysis of climate-related intangible harm from around the world. Glob Environ Change 55:58-72. https://doi.org/10.1016/j.gloenvcha.2018.11.006

Tschakert P, Barnett J, Ellis N, Lawrence C, Tuana N, New M, ELRICK-BARR C, Pandit R, Pannell D (2017) Climate change and loss, as if people mattered: values, places, and experiences. Wiley Interdisciplinary Reviews-Climate Change 8

U.S. Census Bureau (2018) TIGER/Line Shapefiles and TIGER/Line Files Technical Documentation

U.S. Census Bureau (2021) QuickFacts: Gulf County, Florida. Retrieved October 18, from https://www.census. gov/quickfacts/gulfcountyflorida

van der Geest K (2018) Landslide loss and damage in Sindhupalchok District, Nepal: comparing income groups with implications for compensation and relief. Int J Disaster Risk Sci 9(2):157-166. https://doi.org/10. 1007/s13753-018-0178-5 
Vickery PJ, Skerlj PF, Lin J, Twisdale LA, Young MA, Lavelle FM (2006) HAZUS-MH Hurricane model methodology. Damage loss estimation. Nat Hazards Rev II(2):94-103

Winston N, Eastaway P (2008) Sustainable housing in the urban context: international sustainable development indicator sets and housing. Soc Indic Res 87(2):211-221. https://doi.org/10.1007/s11205-007-9165-8

Wolff EN (2016) Household Wealth Trends in the United States, 1962 to 2013: what happened over the great recession? Russell Sage Found J Soc Sci 2(6):24-43

Zampieri NE, Pau S, Okamoto DK (2020) The impact of Hurricane Michael on longleaf pine habitats in Florida. Sci Rep 10:8483. https://doi.org/10.1038/s41598-020-65436-9

Zhang Y, Peacock WG (2009) Planning for housing recovery? lessons learned from Hurricane Andrew. J Am Plann Assoc 76(1):5-24. https://doi.org/10.1080/01944360903294556

Publisher's Note Springer Nature remains neutral with regard to jurisdictional claims in published maps and institutional affiliations. 